\title{
Rhein enhances the cytotoxicity of effector lymphocytes in colon cancer under hypoxic conditions
}

\author{
XIANGFEI YUAN $^{1 *}$, WENCONG TIAN $^{1 *}$, YANG HUA $^{2}$, LIJUAN HU $^{1}$, \\ JING YANG ${ }^{1}$, JUNMUZI XIE ${ }^{1}$, JIACAI HU ${ }^{1}$ and FENG WANG ${ }^{1}$ \\ ${ }^{1}$ Tianjin Institute of Integrative Medicine for Acute Abdominal Diseases, Tianjin Nankai Hospital, \\ Tianjin 300100; ${ }^{2}$ Department of Colorectal Surgery, Tianjin Union Medical Center, Tianjin 300121, P.R. China
}

Received May 10, 2018; Accepted September 6, 2018

DOI: $10.3892 /$ etm.2018.6855

\begin{abstract}
The immunosuppressive tumor microenvironment limits the application of adoptive immunotherapy for solid tumors. Hypoxia is closely associated with the formation of the immunosuppressive tumor microenvironment. Hypoxia-inducible factor-1 (HIF-1) is an oxygen-sensitive transcriptional activator that drives the transcription of several immunosuppressive molecules. In addition, previous studies confirmed that rhein downregulated the expression of HIF-1 $\alpha$, a subunit of HIF-1, in pancreatic cancer cells. The present study established correlations between mRNA expression levels of HIF- $1 \alpha$ and six immunosuppressive molecules in colorectal cancer (CRC) tissue samples. This study examined the effect of rhein on the expression levels of HIF-1 $\alpha$ and six immunosuppressive molecules in CRC cell lines under hypoxic conditions by western blot analysis and reverse transcription-quantitative polymerase chain reaction. This study demonstrated that rhein downregulated the expression of HIF-1 $\alpha$ and immunosuppressive molecules in CRC cells under hypoxic conditions. In addition, the present study analyzed the cytotoxicity of peripheral blood lymphocytes in vitro using a non-toxic cytotoxicity assay. This study demonstrated that in vitro, rhein enhanced the cytotoxicity of effector lymphocytes toward tumor cells under hypoxic conditions, and therefore rhein may be used in combination with effector lymphocytes for the treatment of CRC.
\end{abstract}

Correspondence to: Dr Xiangfei Yuan or Dr Feng Wang, Tianjin Institute of Integrative Medicine for Acute Abdominal Diseases, Tianjin Nankai Hospital, 6 Changjiang Road, Tianjin 300100, P.R. China

E-mail: yuanxiangfei100@163.com

E-mail: fengwangpi@163.com

*Contributed equally

Key words: rhein, hypoxia, effector lymphocyte, immunosuppressive tumor microenvironment, hypoxia-inducible factor-1, colorectal cancer

\section{Introduction}

The success of CD19-targeted chimeric antigen receptor (CAR) T-cells in hematopoietic malignancies has led to further research surrounding the use of adoptive immunotherapy in the treatment of solid tumors (1). Carcinoembryonic antigen (CEA)-targeted CAR T-cells have previously been used to treat liver and peritoneal metastases of colorectal cancer (CRC) (2-4). However, the application of CAR T-cells for the treatment of solid tumors is limited due to the inherent immunosuppressive tumor microenvironment (5).

Currently, several studies have demonstrated that when tumor cells are exposed to hypoxic conditions, immunosuppressive molecules including programmed cell death ligand-1 (PD-L1), vascular endothelial growth factor (VEGF), cyclooxygenase-2 (COX-2), galectin-1, interleukin (IL)-10 and transforming growth factor-1 (TGF- $\beta 1$ ) are upregulated (6-10). These immunosuppressive factors serve an important role in the immunosuppressive tumor microenvironment inducing T-cell apoptosis, suppressing the maturation of dendritic cells and influencing the differentiation of immune cells (11). In addition, hypoxia-inducible factor-1 (HIF-1) is an important oxygen-sensitive response factor that drives the transcription of several immunosuppressive molecules, which include PD-L1, VEGF, COX-2 and galectin-1 $(6,11)$.

Rhein is a lipophilic anthraquinone mainly extracted from rhizomes of several traditional medicinal plants (12). A previous study revealed that rhein decreased the level of HIF-1 $\alpha$ (a subunit of HIF-1) in tumor cells under hypoxic conditions (13). The present study identified correlations between HIF-1 $\alpha$ and the immunosuppressive molecules in tissue samples from patients with CRC. This study also demonstrated that rhein induces an immunoregulatory effect, downregulating the expression of HIF-1 $\alpha$ and immunosuppressive molecules in CRC cell lines under hypoxic conditions. In addition, rhein enhanced the cytotoxicity of effector lymphocytes toward CRC tumor cells under hypoxic conditions. It may be hypothesized that rhein downregulates the expression of immunosuppressive molecules by inhibiting the expression of HIF-1 $\alpha$ under hypoxic conditions, and as a result this may enhance the cytotoxicity of effector lymphocytes. 


\section{Materials and methods}

Patient samples. Fresh frozen tissue samples from 12 patients (8 males and 4 females aged from 49-83 years old) with CRC were provided by the Department of Colorectal Surgery, Tianjin Union Medical Center (Tianjin, China). All the tissue samples were collected from patients pathologically diagnosed with CRC between Janunary and March 2018, and the characteristics of each patient are summarized in Table I. This study was approved by the Tianjin Nankai Hospital ethics commission (Tianjin, China; approval no. NKYY_YX_IRB_044_01).

Cell culture. The human CRC cell lines, HT29, HCT116, Colo205 and SW620 were obtained from the Tianjin Institute of Integrative Medicine for Acute Abdominal Diseases, Tianjin Nankai Hospital and the 293T cell line was provided by Professor Xiong Dongsheng from the Institute of Hematology \& Blood Diseases Hospital, Chinese Academy of Medical Sciences \& Peking Union Medical College (Tianjin, China). Cells were maintained in Dulbecco's modified Eagle medium (DMEM; cat. no. 1791922; Gibco; Thermo Fisher Scientific, Inc., Waltham, MA, USA) supplemented with $10 \%$ fetal bovine serum (FBS; cat. no. 25030-081; Gibco; Thermo Fisher Scientific, Inc.) at $37^{\circ} \mathrm{C}$. Cells cultured under hypoxic conditions were placed in a hypoxic chamber as previously described $(14,15)$. The air inside the chamber was flushed with a mixture of $\mathrm{N}_{2}(95 \%)$ and $\mathrm{CO}_{2}(5 \%)$ and when the oxygen concentration decreased to $1 \%$, the chamber was sealed and kept at $37^{\circ} \mathrm{C}$.

Peripheral blood lymphocytes (PBLs) were isolated from the blood of healthy donors from the Tianjin Blood Center (Tianjin, China; dataset no. ISCP17021885; tjbc.org.cn) by Ficoll $^{\circledR}$ solution (cat. no. LTS10771; TBD Science, Tianjin, China). The cells were maintained in Roswell Park Memorial Institute-1640 medium (cat. no. 1721503; Gibco; Thermo Fisher Scientific, Inc.) supplemented with $10 \%$ FBS and $100 \mathrm{U} / \mathrm{ml}$ recombinant human IL-2 (cat. no. 202-IL-010; R\&D Systems, Inc., Minneapolis, MN, USA) at $37^{\circ} \mathrm{C}$ every $48 \mathrm{~h}$.

Reverse transcription-quantitative polymerase chain reaction $(R T-q P C R)$. Total RNA was extracted from cells or tissue samples using TRIzol ${ }^{\circledR}$ reagent (cat. no. 15596026; Invitrogen; Thermo Fisher Scientific, Inc.), according to the manufacturer's protocol. Total RNA ( $4 \mu \mathrm{g})$ was reverse transcribed into cDNA using the RevertAid First Strand cDNA Synthesis kit (cat. no. K1622; Thermo Fisher Scientific, Inc.), according to the manufacturer's protocol. qPCR was subsequently performed using the SYBR ${ }^{\circledR}$ Premix Ex Taq ${ }^{\mathrm{TM}}$ kit (cat. no. RR420L; Takara Biotechnology Co., Ltd., Dalian, China). The primer pairs used are presented in Table II, and $\beta$-actin was used as a reference gene for normalization. The following thermocycling conditions were used for the qPCR: Initial denaturation at $95^{\circ} \mathrm{C}$ for $30 \mathrm{sec} ; 40$ cycles of $95^{\circ} \mathrm{C}$ for $5 \mathrm{sec}$ and $60^{\circ} \mathrm{C}$ for $34 \mathrm{sec}$. To analyze the correlation of gene expression in tumor tissues of patients with CRC, the $\mathrm{Cq}$ values from patient 1 were used as a baseline to correlate the $\mathrm{Cq}$ values of other patients, and the Pearson product-moment correlation coefficient (Pearson's R) was measured. Relative gene expression in CRC cell lines was quantified using the $2^{-\Delta \Delta \mathrm{Cq}}$ method (16). These experiments were repeated in triplicate.
Cell viability assay. Cells were seeded onto 96-well plates at a density of $1 \times 10^{4}$ cells/well and treated with $0,12.5,25$, 50, 100 or $200 \mu \mathrm{M}$ rhein (cat. no. SG8100; Beijing Solarbio Science \& Technology Co., Ltd., Beijing, China) for $48 \mathrm{~h}$. Then the purple formazan were dissolved in DMSO (cat. no. D8371-50; Beijing Solarbio Science \& Technology Co., Ltd.) and measured at a wavelength of $492 \mathrm{~nm}$. In CRC cell lines, cell viability was measured by MTT reduction assay (cat. no. M2128; Sigma-Aldrich, Merck KGaA, Darmstadt, Germany). In PBLs, cell viability was measured by cell counting kit-8 (cat. no. CK04; Dojindo Molecular Technologies, Inc., Kumamoto, Japan) as manufacturer's protocol. Untreated cells were used as a negative control and cell viability was set as $100 \%$.

Establishment of a cell line stably expressing the membrane-bound single chain Fv against CD3 (mCD3scfv). The mCD3scfv sequence was provided by Professor Xiong Dongsheng and amplified by PCR using Pyrobest ${ }^{\mathrm{TM}}$ DNA Polymerase (cat. no. R005A; Takara Biotechnology Co., Ltd.) and the following primers: 5'-CGTAGAATTCGCCACCAT GGAGACAGACACACTCCTG-3' and 5'-CGTAGGATCCCT AACGTGGCTTCTTCTGCC-3'. The thermocycling condition was as follows: Initial denaturation at $95^{\circ} \mathrm{C}$ for $5 \mathrm{~min} ; 35$ cycles of $95^{\circ} \mathrm{C}$ for $10 \mathrm{sec}, 60^{\circ} \mathrm{C}$ for $60 \mathrm{sec}$ and $72^{\circ} \mathrm{C}$ for $60 \mathrm{sec}$. The PCR product was purified and cloned into the lentiviral expression vector pCDH1-CMV-MSC-EF1 $\alpha$-Puro (cat. no. CD510B-1; System Biosciences, LLC., Palo Alto, CA, USA) using EcoRI and BamHI restriction sites. The lentiviral expression construct was co-transfected with backbone plasmids [5 $\mu \mathrm{g}$ MD2G, $3 \mu \mathrm{g}$ PAX2 (Invitrogen; Thermo Fisher Scientific, Inc.) and $7 \mu \mathrm{g}$ pCDH1] in $293 \mathrm{~T}$ cells using X-tremeGENE ${ }^{\mathrm{TM}}$ HP DNA transfection reagent (cat. no. 06366236001; Roche Molecular Diagnostics, Pleasanton, CA, USA) to produce the lentivirus (17). HT29 cells were transduced with the lentivirus for $48 \mathrm{~h}$ and selected with $30 \mu \mathrm{g} / \mathrm{ml}$ puromycin (cat. no. P8230; Beijing Solarbio Science \& Technology Co., Ltd.) for 2 weeks. The HT29 cell line stably expressing mCD3scfv, was termed HT29-CD3scfv.

Western blot analysis. Total protein was extracted from cells using radioimmunoprecipitation lysis buffer (cat. no. R0010) and the protein concentration was determined by BCA Protein Assay kit (cat. no. PC0020; both Beijing Solarbio Science \& Technology Co., Ltd.). The proteins were separated using SDS-PAGE (10\% polyacrylamide gel; $40 \mu \mathrm{g}$ total protein per lane) and transferred onto polyvinylidene difluoride membranes (cat. no. IPVH00010; EMD Millipore, Billerica, MA, USA). Membranes were blocked by 5\% skim milk at room temperature for $4 \mathrm{~h}$ and then incubated with primary antibodies (1:500) against HIF-1 $\alpha$ (cat. no. 100-449), $\beta$-tubulin (cat. no. 66240-1; both 1:500; Wuham Sanying Biotechnology, Inc., Wuhan, China), and HA-tag (cat. no. ab1818; 1:500; Abcam, Cambridge, MA, USA) overnight at $4^{\circ} \mathrm{C}$. Following primary incubation, membranes were incubated with horseradish peroxidase-conjugated goat anti-mouse (cat. no. SE12) or anti-rabbit (cat. no. SE13) secondary antibodies (both 1;2,000; Beijing Solarbio Science $\&$ Technology Co., Ltd.) for $1 \mathrm{~h}$ at room temperature. Protein bands were visualized using the BioVision ECL Western 
Table I. Patient information.

\begin{tabular}{llcl}
\hline Patient no. & Sex & Age, years & Tumor location \\
\hline 1 & Female & 57 & Sigmoid colon \\
2 & Male & 83 & Ascending colon \\
3 & Male & 61 & Ascending colon \\
4 & Male & 64 & Ascending colon \\
5 & Female & 50 & Descending colon \\
6 & Male & 62 & Sigmoid colon \\
7 & Female & 69 & Ascending colon \\
8 & Male & 67 & Transverse colon \\
9 & Male & 58 & Descending colon \\
10 & Male & 62 & Ileocecus \\
11 & Male & 70 & Descending colon \\
12 & Female & 49 & Ascending colon \\
\hline
\end{tabular}

Blotting Substrate kit (cat. no. K820-500; BioVision, Inc., Milpitas, CA, USA).

Immunofluorescence. HT29-CD3scfv or HT29-control cells were fixed with $4 \%$ paraformaldehyde for $10 \mathrm{~min}$ and blocked with $1 \%$ bovine serum albumin (cat. no. A8010; Beijing Solarbio Science \& Technology Co., Ltd.) for $1 \mathrm{~h}$. Cells were incubated with mouse anti-HA-tag primary antibody (cat. no. ab18181) for $1 \mathrm{~h}$, followed by incubation with allophycocyanin (APC)-conjugated goat anti-mouse IgG (cat. no. ab130782; both 1:1,000; Abcam) secondary antibody for $1 \mathrm{~h}$. Cells were stained with DAPI (Sigma-Aldrich, Merck $\mathrm{KGaA}$ ) for $5 \mathrm{~min}$. All the steps were performed at room temperature. Images were captured using a two-photon laser scanning confocal microscope (Olympus Corporation, Tokyo, Japan; FV1200 MPE).

Flow cytometry. HT29-CD3scfv or HT29-control cells were incubated with mouse anti-HA tag primary antibody (cat. no. ab18181; 1:1,000; Abcam) for $30 \mathrm{~min}$ at room temperature. Following primary incubation, cells were washed twice using PBS and incubated with APC-conjugated goat anti-mouse IgG (cat. no. ab130782; 1:1,000; Abcam) secondary antibody for $30 \mathrm{~min}$ at room temperature. Following one wash by PBS, cells were analyzed using a flow cytometer (BD Biosciences, Franklin Lakes, NJ, USA; FACS LSRII). The data were analyzed by FlowJo software (version 7.6; Tree Star, Inc., Ashland, OR, USA).

Cytotoxicity assays of PBLs. The specific lysis of target cells was measured by lactate dehydrogenase release assay using the CytoTox $96^{\circledR}$ Non-Radioactive Cytotoxicity Assay kit (Promega Corporation, Madison, WI, USA) according to the manufacturer's protocol. HT29 and HT29-CD3scfv cells were seeded onto 96 well plates $\left(1 \times 10^{4}\right.$ cells/well $)$ as target cells. PBLs were added at different effector-to-target (E:T) cell ratios 5:1, 10:1 and 20:1 to 96-well culture plates and co-cultured with target cells for $16 \mathrm{~h}$.

For assessment under hypoxic conditions, HT29-CD3scfv cells were pretreated with or without $50 \mu \mathrm{M}$ rhein for $8 \mathrm{~h}$.
Untreated cells in normoxia were used as the negative control. PBLs were subsequently added at different E:T cell ratios and co-cultured with target cells for $16 \mathrm{~h}$, and specific cytotoxicity was detected as described above.

Statistical analysis. The results are reported as the mean \pm standard deviation of at least three independent experiments. All experimental data were analyzed using one-way analysis of variance (ANOVA) with Dunnett's post-test. The strength of a linear association between two variables was calculated with the Pearson product-moment correlation coefficient (Pearson's R coefficient). Pearson's R coefficient and ANOVA were performed using GraphPad Prism 5 software (GraphPad Software Inc., La Jolla, CA, USA). P $<0.05$ was considered to indicate a statistically significant difference.

\section{Results}

HIF-1 $\alpha$ correlates with several immunosuppressive factors in $C R C$. To determine the effect of HIF-1 $\alpha$ in CRC, the mRNA expression levels of HIF- $1 \alpha$ and six immunosuppressive molecules were determined by RT-qPCR from 12 CRC tumor tissue samples. The correlation between the mRNA expression level of HIF-1 $\alpha$ and the six immunosuppressive molecules was analyzed by Pearson's R coefficient. The mRNA expression levels of PD-L1, VEGF, COX-2, and galectin-1 were positively correlated with that of HIF-1 $\alpha$ in CRC tissues (Fig. 1). However, there was no significant correlation between HIF-1 $\alpha$ and IL-10 or TGF- $\beta 1$ in the CRC tissue samples analyzed.

Rhein cytotoxicity. To determine the effect of rhein in CRC, cell viability was examined using the MTT and CCK-8 assays. The MTT assay was performed in CRC cell lines (HT29, HCT116, Colo205, SW620) following treatment with rhein $(12.5,25$, $50,100$ and $200 \mu \mathrm{M})$ for $48 \mathrm{~h}$. Rhein $(100$ and $200 \mu \mathrm{M})$ significantly decreased cell viability in a what appeared to be a dose-dependent manner in all four CRC cell lines $(\mathrm{P}<0.05$; Fig. 2A). The CCK-8 assay was performed in PBLs following treatment with rhein $(25$ or $50 \mu \mathrm{M})$ for $48 \mathrm{~h}$. Rhein had no affect on PBL cell viability (Fig. 2B).

Rhein downregulates the expression of HIF-1 $\alpha$ and immunosuppressive molecules in hypoxic conditions. To determine the inhibitory effect of rhein in hypoxia, the expression levels of HIF-1 $\alpha$ and six immunosuppressive molecules were examined using western blotting in HT29 cells cultured in 4 conditions: Normoxia, hypoxia, hypoxia $+25 \mu \mathrm{M}$ rhein, and hypoxia $+50 \mu \mathrm{M}$ rhein for $16 \mathrm{~h}$. The protein expression level of HIF-1 $\alpha$ was increased in hypoxia, compared with normoxia. Additionally, rhein markedly decreased the protein expression level of HIF-1 $\alpha$ under hypoxic conditions in a dose-dependent manner (Fig. 3A). The mRNA levels of six immunosuppressive molecules were detected by RT-qPCR . Similar to HIF-1 $\alpha$ protein expression, the mRNA expression levels of PD-L1, VEGF, COX-2, galectin-1, IL-10 and TGF- $\beta 1$ were upregulated in hypoxia, compared with normoxia. Rhein significantly decreased the mRNA expression levels under hypoxic conditions in a dose-dependent manner (Fig. 3B). These results demonstrated that the mechanism underlying the inhibitory effect of rhein may be HIF-1 $\alpha$-dependent. Although 
Table II. Quantitative polymerase chain reaction primer sequences.

Primer sequence $\left(5^{\prime} \rightarrow 3^{\prime}\right)$

Gene

Forward

Reverse

HIF- $1 \alpha$

PD-L1

VEGF

COX-2

Galectin-1

IL-10

TGF- $\beta$

$\beta$-actin
TGATTGCATCTCCATCTCCTACC

TGTACCGCTGCATGATCAG

ACTGAGGAGTCCAACATCAC

GGTCTGGTGCCTGGTCTGAT

CGCTAAGAGCTTCGTGCTGAAC

GCCTTGTCTGAGATGATCCAGTT

GGGAAATTGAGGGCTTTCG

GGACATCCGCAAAGACCTGTA
GACTCAAAGCGACAGATAACACG

AGTTCATGTTCAGAGGTGACTG

GTCTGCATTCACATTTGTTG

TCCTGTTTAAGCACATCGCATACT

CACACCTCTGCAACACTTCCAG

TCACATGCGCCTTGATGTCT

GAACCCGTTGATGTCCACTTG

GCATCCTGTCGGCAATGC

HIF-1 $\alpha$, hypoxia-inducible factor 1 subunit $\alpha$; PD-L1, programmed cell death 1 ligand 1; VEGF, vascular endothelial growth factor; COX-2, cyclooxygenase-2, IL-10, interleukin 10; TGF- $\beta 1$, transforming growth factor $\beta-1$.
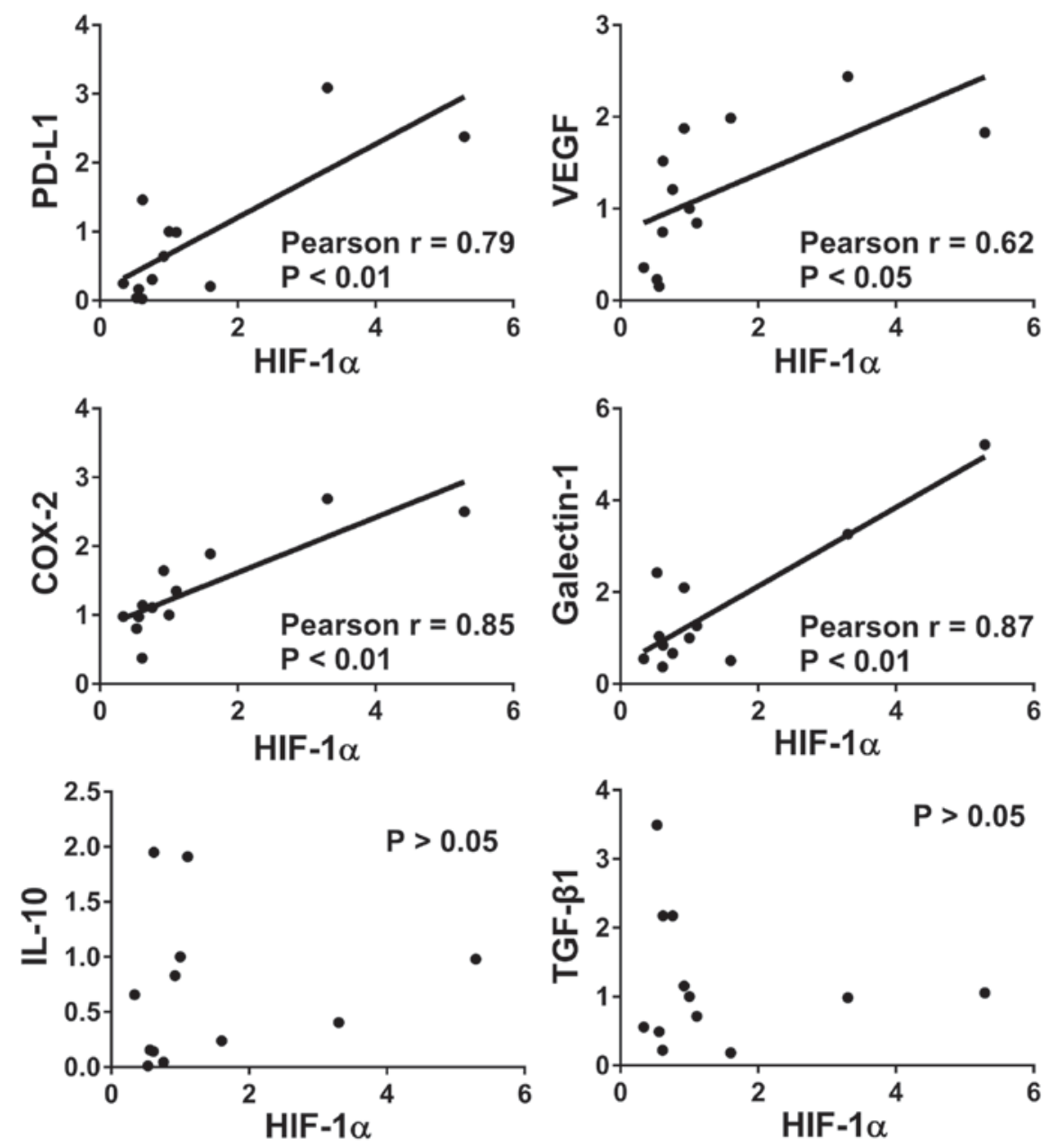

Figure 1. HIF-1 $\alpha$ mRNA expression correlates with immunosuppressive gene expression in colorectal cancer tissue. The expression levels of HIF-1 $\alpha$ and six genes with known immunosuppressive functions were determined by reverse transcription-quantitative polymerase chain reaction from 12 colorectal cancer tissue samples. The Pearson's R coefficient was used to measure the correlation between the mRNA expression level of HIF-1 $\alpha$ and the six immunosuppressive molecules. HIF-1 $\alpha$, hypoxia-inducible factor 1 subunit $\alpha$; PD-L1, programmed cell death 1 ligand 1; COX-2, cyclooxygenase-2; IL-10, interleukin 10; VEGF, vascular endothelial growth factor; TGF-1 $\beta$, transforming growth factor $\beta-1$.

the mRNA expression levels of IL-10 and TGF- $\beta 1$ were also downregulated following treatment with rhein under hypoxic conditions (Fig. 3B), there was no correlation between HIF-1 $\alpha$ and IL-10 or TGF- $\beta 1$ observed (Fig. 1). These results identified a potential HIF- $1 \alpha$-independent mechanism underlying the inhibitory effect of rhein. 

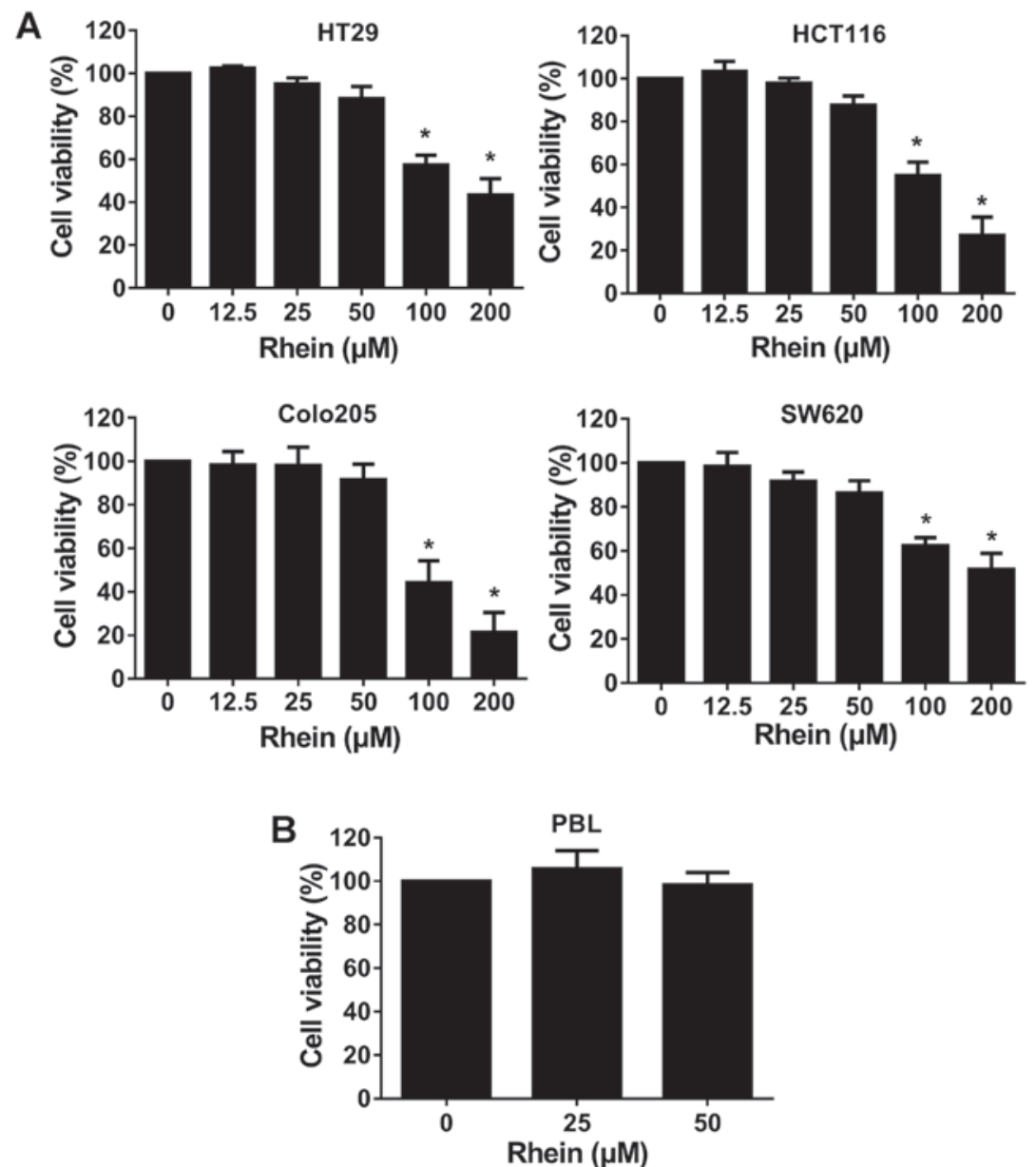

Figure 2. Rhein cytotoxicity in CRC cell lines and PBLs. (A) MTT assay was used to examine cell viability in four CRC cell lines following treatment with various concentrations of rhein for $48 \mathrm{~h}$. ${ }^{*} \mathrm{P}<0.05$ vs. untreated cells. (B) Cell counting kit- 8 assay was used to examine cell viability in PBL following treatment with rhein for $48 \mathrm{~h}$. Data are presented as the mean \pm standard deviation and normalized to untreated control. CRC, colorectal cancer, PBL, peripheral blood lymphocyte; HT29, HCT116, Colo205 and SW620, human CRC cell lines.

Cytotoxicity of PBLs toward HT29-CD3scfv cells. To examine the cytotoxicity of PBLs in CRC, a CRC cell model specifically recognized by PBLs was established using a lentivirus containing the membrane-bound anti-CD3scFv expression cassette (Fig. 4A). HT29 cells were transduced with the lentiviral vector or blank control for $48 \mathrm{~h}$ and then selected with puromycin for an additional 2 weeks. To identify HT29 cells stably expressing mCD3scfv, western blot analysis, confocal microscopy and flow cytometry were used to detect the $\mathrm{N}$-terminal HA-tag of the fusion protein. The results revealed that mCD3scfv was expressed in HT29-CD3scfv cells and mCD3scfv localized on the cell membrane (Fig. 4B and C). Furthermore, HT29 cells expressing the fusion protein accounted for $96.8 \%$ of the total HT29-CD3scfv cells examined (Fig. 4D). Finally, HT29-CD3scfv and HT29-control target cells were co-cultured with PBLs at different E:T cell ratios, respectively for $16 \mathrm{~h}$. CytoTox $96^{\circledR}$ non-radioactive cytotoxicity assays revealed that PBLs were cytolytic toward HT29-CD3scfv cells. Their cytotoxic effect increased as the E:T ratio using PBLs as effector cells and HT29-CD3scfv cells as target cells increased. PBLs were slightly cytolytic toward HT29-control cells. Furthermore, the cytotoxity of HT29-CD3scfv singicantly increase compared with
HT29-control cells at the corresponding E:T ratio $(\mathrm{P}<0.05$; Fig. 4E).

Rhein enhances the cytotoxicity of PBLs in hypoxia. To further examine the inhibitory effect of rhein in hypoxia, the cytotoxicity of PBLs toward CRC cells was examined following treatment with rhein under hypoxic conditions. HT29-CD3scfv cells were cultured under conditions of normoxia, hypoxia and hypoxia $+50 \mu \mathrm{M}$ rhein, followed by co-culture with PBLs at different effector-to-target cell ratios (5:1, 10:1 and 20:1). CytoTox $96^{\circledR}$ non-radioactive cytotoxicity assays revealed that PBLs are cytolytic toward HT29-CD3scfv cells, and their cytotoxic effect was inhibited by hypoxia. Treatment with rhein enhanced the cytotoxicity of PBLs in hypoxia, compared with normoxia (Fig. 5).

\section{Discussion}

Since the expression of HIF-1 $\alpha$ is inhibited by rhein (13), it may be hypothesized that rhein downregulates immunosuppressive molecules driven by HIF-1 and further enhances the anti-tumor effect of PBLs in hypoxia. The present study investigated the correlation between the mRNA levels of HIF-1 $\alpha$ and the six 

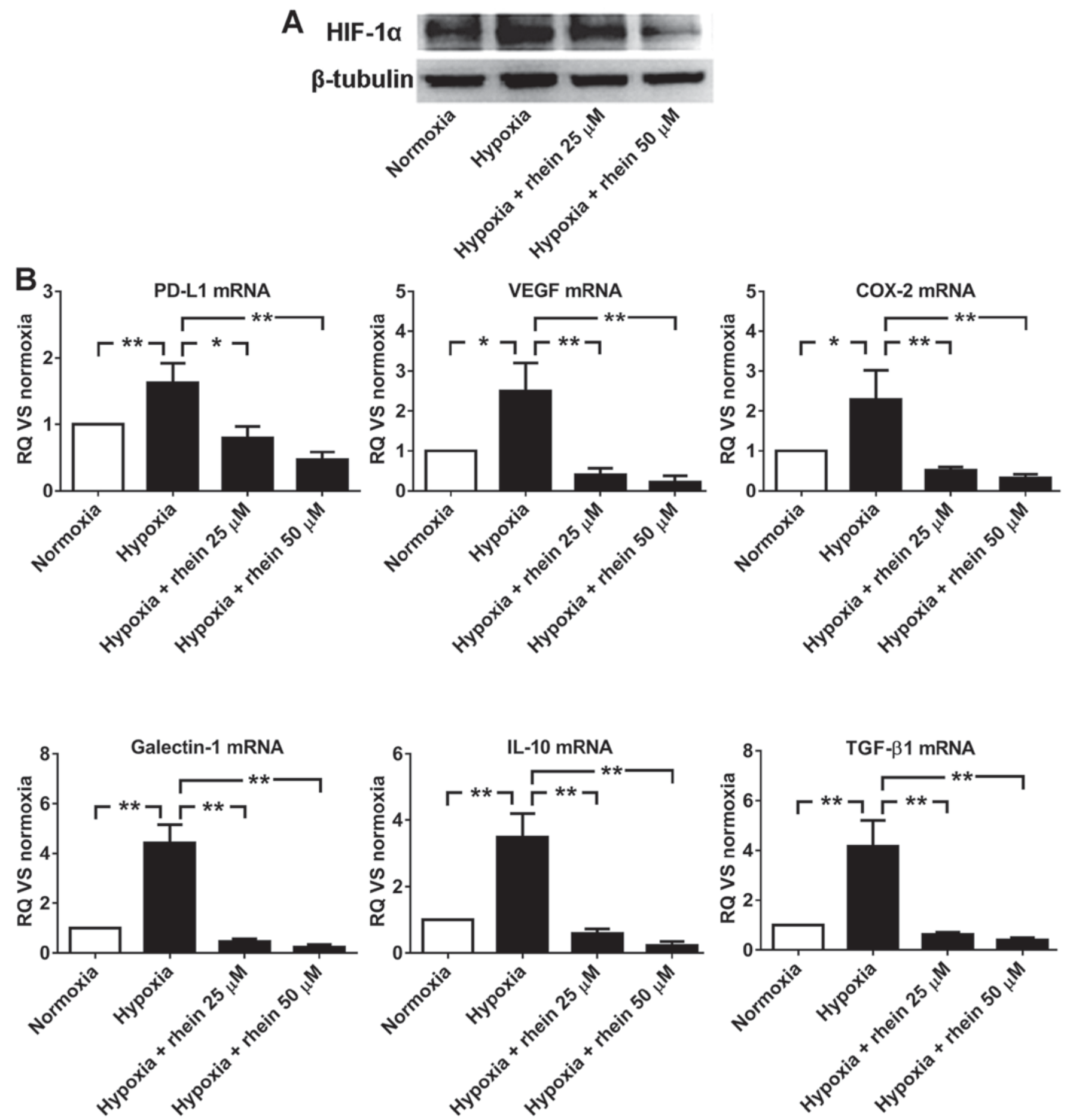

Figure 3. Rhein downregulates the expression of HIF-1 $\alpha$ and six immunosuppressive molecules. (A) The protein expression levels of HIF-1 $\alpha$ were determined by western blot analysis in HT29 cells cultured under conditions of normoxia, hypoxia, hypoxia $+25 \mu \mathrm{M}$ rhein, and hypoxia $+50 \mu \mathrm{M}$ rhein for $16 \mathrm{~h}$. (B) The mRNA expression levels of PD-L1, VEGF, COX-2, galectin-1, IL-10 and TGF- $\beta 1$ were determined by reverse transcription-quantitative polymerase chain reaction in HT29 cells treated as above. The mRNA expression levels were normalized to that of cells under normoxia. The data are presented as the mean \pm standard deviation from three independent experiments. ${ }^{*} \mathrm{P}<0.05$ and ${ }^{* *} \mathrm{P}<0.01$ as indicated. RQ, relative quantification; CRC, colorectal cancer; HIF-1 $\alpha$ hypoxia-inducible factor 1 subunit $\alpha$; PD-L1, programmed cell death 1 ligand 1; COX-2, cyclooxygenase-2; IL-10, interleukin 10; VEGF, vascular endothelial growth factor; TGF- $\beta 1$, transforming growth factor- $\beta 1$; HT29, human CRC cell line.

immunosuppressive molecules in tumor tissue samples from patients with CRC. The mRNA expression of four immunosuppressive molecules positively correlated with HIF-1 $\alpha$, however IL-10 and TGF- $\beta 1$ did not correlate with HIF- $1 \alpha$ expression. The expression levels of HIF-1 $\alpha$ and the six immunosuppressive molecules were upregulated in hypoxia, however the addition of rhein significantly decreased the mRNA expression levels under hypoxic conditions. These results indicated that the mechanism underlying the inhibitory effect of rhein may be HIF-1 $\alpha$-dependent. However, the mRNA expression levels of IL-10 and TGF- $\beta 1$ were downregulated following treatment with rhein under hypoxic conditions without the observed correlation 


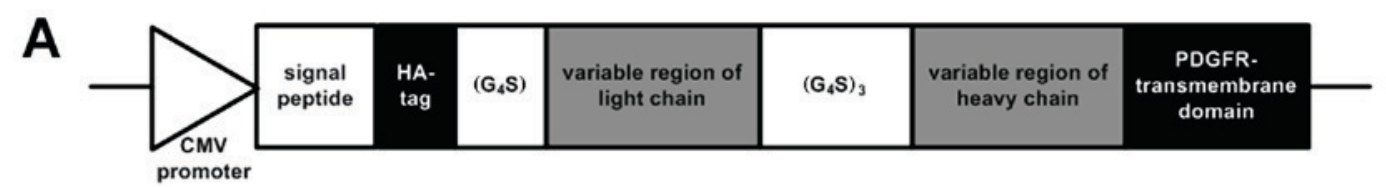

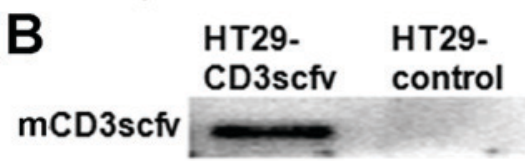

$\beta$-tubulin
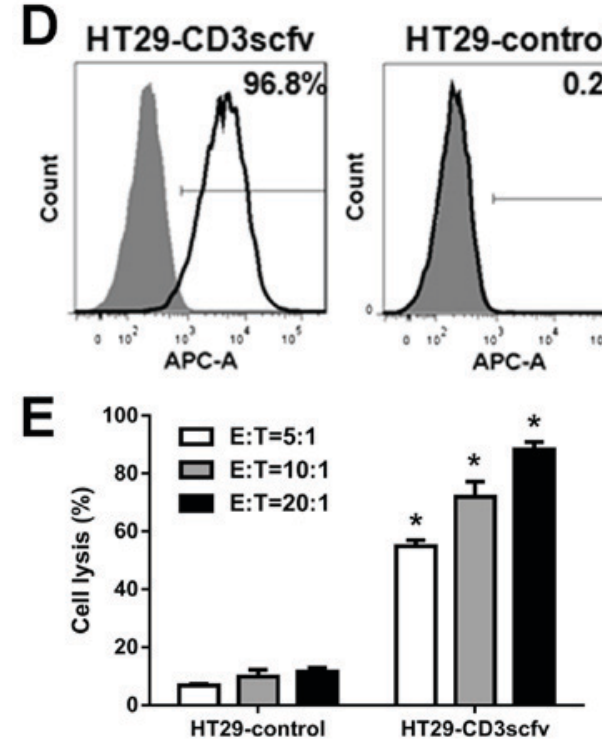

C

DAPI
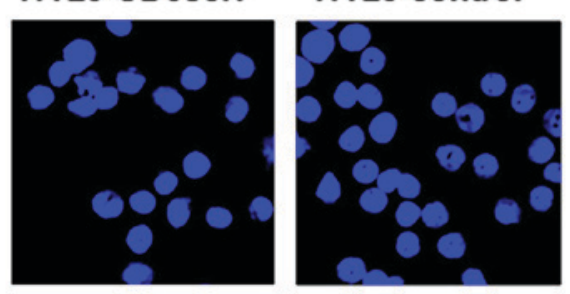

merge
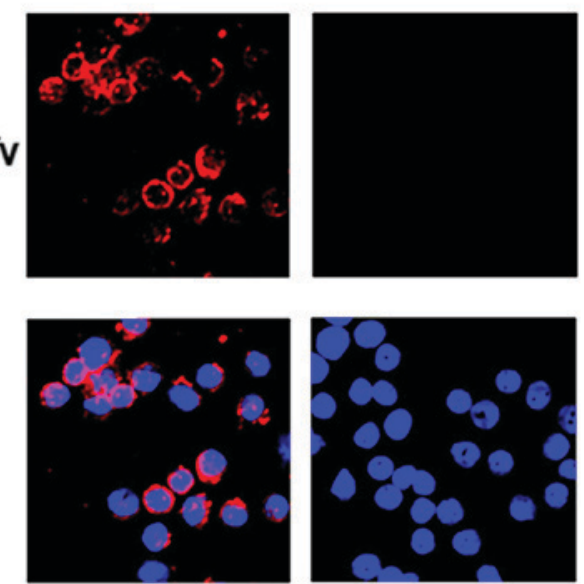

Figure 4. Cytotoxicity of PBLs toward HT29-CD3scfv cells. (A) Schematic representation of the lentiviral vector construct encoding membrane-bound anti-CD3scfv expression cassette. (B) The protein expression levels of CD3scfv in HT29-CD3scfv and HT29-control cells were determined by western blot analysis. (C) The cellular localization of CD3scfv in HT29-CD3scfv and HT29-control cells was detected by confocal microscopy (magnification, x400). (D) The proportion of cells expressing membrane-bound anti-CD3scfv was determined by fluorescence-activated cell sorting analysis. (E) HT29-CD3scfv and HT29-control cells were co-cultured with PBLs at different E:T cell ratios, respectively for 16 h. CytoTox $96^{\circledR}$ Non-Radioactive Cytotoxicity assay was used to determine cell lysis of HT29-CD3scfv and HT29-control cells. The data are presented as the mean \pm standard deviation from three independent experiments. "P<0.05 vs. HT29-control cells at the corresponding E:T ratio. HT29-control, untreated HT29 cells; HT29-CD3scfv, HT29 cells stably expressing mCD3scfv; HT29, human CRC cell line; PBL, peripheral blood lymphocyte; CRC, colorectal cancer; HA, hemagglutinin; E:T, effector-to-target cell ratio.

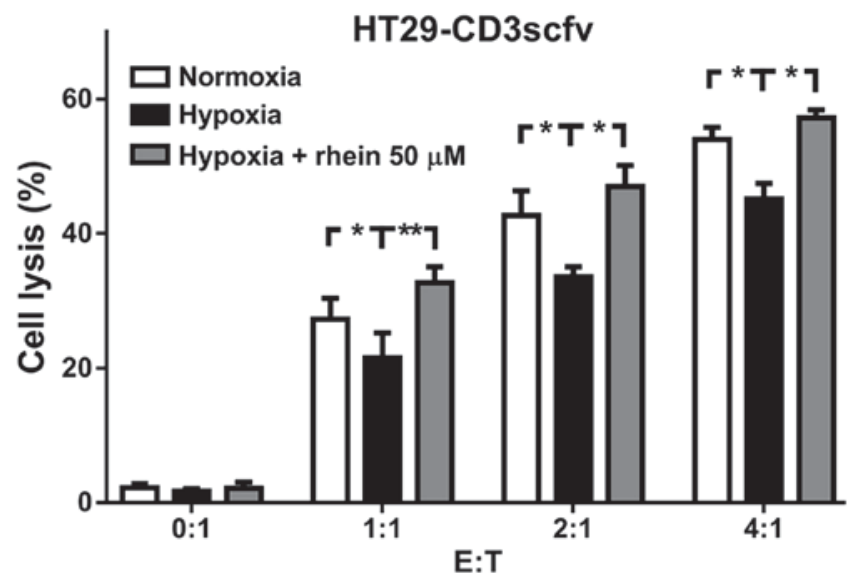

Figure 5. Rhein enhances the cytotoxicity of PBLs in hypoxia. HT29-CD3scfv cells were cultured under conditions of normoxia, hypoxia and hypoxia $+50 \mu \mathrm{M}$ rhein for $8 \mathrm{~h}$. Cells were subsequently co-cultured with PBLs at different E:T cell ratios for $16 \mathrm{~h}$. HT29-CD3scfv cell lysis was examined by CytoTox $96^{\circledR}$ Non-Radioactive Cytotoxicity assay. The data are presented as the mean \pm standard deviation from three independent experiments. ${ }^{*} \mathrm{P}<0.05$ and ${ }^{* *} \mathrm{P}<0.01$ as indicated. PBLs, peripheral blood lymphocytes; HT29-CD3scfv, HT29 cells stably expressing mCD3scfv; E:T, effector-to-target cell ratio. with HIF-1 $\alpha$, which indicated a potential HIF-1 $\alpha$-independent mechanism underlying the inhibitory effect of rhein in hypoxia. Furthermore, the current study demonstrated that hypoxic conditions reduced the anti-tumor effect of PBLs. However, the addition of rhein under these conditions enhanced the anti-tumor effect of PBLs in CRC cells.

Although the present study demonstrated that rhein enhanced the cytotoxicity of PBLs on CRC cells in hypoxia, there are several limitations that should be noted. Despite having no effect on the viability of PBLs, other regulatory functions of rhein on effector lymphocytes were not addressed in this study and will need further investigation. Furthermore, the role of HIF-1 $\alpha$ in T-cells is controversial and needs further investigation. Some studies suggested that the activity of T-cells in the tumor microenvironment is dependent on the energy supplied by the increased expression of HIF-1 $(18,19)$, however, other studies have demonstrated that the inhibition of HIF-1 $\alpha$ may transform T-cells into memory cells, as well as enhancing the effect of cancer vaccines (20-22). The effect of rhein on metabolism and effector T-cell activity is under investigation. Additionally, immunosuppressive molecules and immunosuppressive cells, which include tumor-associated macrophages, 
myeloid-derived suppressor cells and regulatory T-cells, are components of the immunosuppressive tumor microenvironment and the immunosuppressive function of these cells is dependent on immunosuppressive molecules and HIF (23-25). Additional in vivo studies investigating the effects of rhein with respect to the proportion of immunosuppressive cells in the tumor and infiltration of effector lymphocytes are necessary.

In conclusion, the current study validated the hypothesis that rhein, a down-regulator of HIF-1 $\alpha$, inhibited the expression of immunosuppressive molecules in CRC cells and enhance the cytotoxicity of effector lymphocytes under hypoxic conditions. It was revealed that HIF-1 $\alpha$ positively correlated with immunosuppressive molecules in CRC tissues, and rhein decreased the mRNA levels of HIF-1 $\alpha$ and immunosuppressive molecules in CRC cell lines, and increased the cytotoxicity of effector lymphocytes to HT29-CD3scfv cells in hypoxia. These results indicate that rhein may have great potential to combine with effector T lymphocytes for the treatment of CRC.

\section{Acknowledgements}

The authors would like to thank Professor Xiong Dongsheng from the Institute of Hematology \& Blood Diseases Hospital, Chinese Academy of Medical Sciences \& Peking Union Medical College (Tianjin, China) for providing the 293T cell line and the mCD3scfv sequence.

\section{Funding}

National Natural Science Foundation of China (Grant no. 81572318).

\section{Availability of data and materials}

Not applicable.

\section{Authors' contributions}

XY and FW designed the study. XY, WT and LH performed the experiments. JX and JH analyzed the data. YH and JY collected the human tissue samples.

\section{Ethics approval and consent to participate}

The current study was approved by the Tianjin Nankai Hospital ethics commission (approval no. NKYY_YX_IRB_044_01).

\section{Patient consent for publication}

Not applicable.

\section{Competing interests}

The authors declare that they have no competing interests.

\section{References}

1. Davila ML, Bouhassira DC, Park JH, Curran KJ, Smith EL, Pegram HJ and Brentjens R: Chimeric antigen receptors for the adoptive $\mathrm{T}$ cell therapy of hematologic malignancies. Int $\mathrm{J}$ Hematol 99: 361-371, 2014.
2. Burga RA, Thorn M, Point GR, Guha P, Nguyen CT, Licata LA, DeMatteo RP, Ayala A, Joseph Espat N, Junghans RP and Katz SC: Liver myeloid-derived suppressor cells expand in response to liver metastases in mice and inhibit the anti-tumor efficacy of anti-CEA CAR-T. Cancer Immunol Immunother 64: 817-829, 2015.

3. Katz SC, Point GR, Cunetta M, Thorn M, Guha P, Espat NJ, Boutros C, Hanna N and Junghans RP: Regional CAR-T cell infusions for peritoneal carcinomatosis are superior to systemic delivery. Cancer Gene Ther 23: 142-148, 2016.

4. Katz SC, Burga RA, McCormack E, Wang LJ, Mooring W, Point GR, Khare PD, Thorn M, Ma Q, Stainken BF, et al: Phase I hepatic immunotherapy for metastases study of intra-arterial chimeric antigen receptor-modified T-cell therapy for CEA+ liver metastases. Clin Cancer Res 21: 3149-3159, 2015.

5. Guo Y, Wang Y and Han W: Chimeric antigen receptor-modified $\mathrm{T}$ cells for solid tumors: Challenges and prospects. J Immunol Res 2016: 3850839, 2016.

6. Barsoum IB, Smallwood CA, Siemens DR and Graham CH: A mechanism of hypoxia-mediated escape from adaptive immunity in cancer cells. Cancer Res 74: 665-674, 2014.

7. Gabrilovich D: Mechanisms and functional significance of tumourinduced dendritic-cell defects. Nat Rev Immunol 4: 941-952, 2004.

8. Greenhough A, Smartt HJ, Moore AE, Roberts HR, Williams AC, Paraskeva $\mathrm{C}$ and Kaidi A: The COX-2/PGE2 pathway: Key roles in the hallmarks of cancer and adaptation to the tumour microenvironment. Carcinogenesis 30: 377-386, 2009.

9. Zhao XY, Chen TT, Xia L, Guo M, Xu Y, Yue F, Jiang Y, Chen GQ and Zhao KW: Hypoxia inducible factor-1 mediates expression of galectin-1: The potential role in migration/invasion of colorectal cancer cells. Carcinogenesis 31: 1367-1375, 2010.

10. Hao NB, Lü MH, Fan YH, Cao YL, Zhang ZR and Yang SM: Macrophages in tumor microenvironments and the progression of tumors. Clin Dev Immunol 2012: 948098, 2012.

11. Barsoum IB, Koti M, Siemens DR and Graham CH: Mechanisms of hypoxia-mediated immune escape in cancer. Cancer Res 74: 7185-7190, 2014.

12. Sun H, Luo G, Chen D and Xiang Z: A comprehensive and system review for the pharmacological mechanism of action of rhein, an active anthraquinone ingredient. Front Pharmacol 7: 247, 2016.

13. Hu L, Cui R, Liu H and Wang F: Emodin and rhein decrease levels of hypoxia-inducible factor- $1 \alpha$ in human pancreatic cancer cells and attenuate cancer cachexia in athymic mice carrying these cells. Oncotarget 8: 88008-88020, 2017.

14. Ma F, Hu L, Yu M and Wang F: Emodin decreases hepatic hypoxia-inducible factor-1 $\alpha$ by inhibiting its biosynthesis. Am J Chin Med 44: 997-1008, 2016.

15. Wang F, Li SS, Segersvärd R, Strömmer L, Sundqvist KG, Holgersson J and Permert J: Hypoxia inducible factor-1 mediates effects of insulin on pancreatic cancer cells and disturbs host energy homeostasis. Am J Pathol 170: 469-477, 2007.

16. Livak KJ and Schmittgen TD: Analysis of relative gene expression data using real-time quantitative PCR and the 2(-Delta Delta C(T)) method. Methods 25: 402-408, 2001.

17. Zhang X, Yang Y, Zhang L, Lu Y, Zhang Q, Fan D, Zhang Y, Zhang Y, Ye Z and Xiong D: Mesenchymal stromal cells as vehicles of tetravalent bispecific Tandab (CD3/CD19) for the treatment of B cell lymphoma combined with IDO pathway inhibitor D-1-methyl-tryptophan. J Hematol Oncol 10: 56, 2017.

18. Xu Y, Chaudhury A, Zhang M, Savoldo B, Metelitsa LS, Rodgers J, Yustein JT, Neilson JR and Dotti G: Glycolysis determines dichotomous regulation of T cell subsets in hypoxia. J Clin Invest 126: 2678-2688, 2016.

19. Ottensmeier CH, Perry KL, Harden EL, Stasakova J, Jenei V, Fleming J, Wood O, Woo J, Woelk CH, Thomas GJ and Thirdborough SM: Upregulated glucose metabolism correlates inversely with CD8+ T-cell infiltration and survival in squamous cell carcinoma. Cancer Res 76: 4136-4148, 2016.

20. Tao JH, Barbi J and Pan F: Hypoxia-inducible factors in T lymphocyte differentiation and function. A review in the theme: Cellular responses to hypoxia. Am J Physiol Cell Physiol 309: C580-C589, 2015.

21. Sukumar M, Liu J, Ji Y, Subramanian M, Crompton JG, Yu Z, Roychoudhuri R, Palmer DC, Muranski P, Karoly ED, et al: Inhibiting glycolytic metabolism enhances CD8+ T cell memory and antitumor function. J Clin Invest 123: 4479-4488, 2013. 
22. Kheshtchin N, Arab S, Ajami M, Mirzaei R, Ashourpour M, Mousavi N, Khosravianfar N, Jadidi-Niaragh F, Namdar A, Noorbakhsh F, et al: Inhibition of HIF-1 $\alpha$ enhances anti-tumor effects of dendritic cell-based vaccination in a mouse model of breast cancer. Cancer Immunol Immunother 65: 1159-1167, 2016.

23. Doedens AL, Stockmann C, Rubinstein MP, Liao D, Zhang N, DeNardo DG, Coussens LM, Karin M, Goldrath AW and Johnson RS: Macrophage expression of hypoxia-inducible factor-1 alpha suppresses T-cell function and promotes tumor progression. Cancer Res 70: 7465-7475, 2010.
24. Noman MZ, Desantis G, Janji B, Hasmim M, Karray S, Dessen P, Bronte $\mathrm{V}$ and Chouaib S: PD-L1 is a novel direct target of HIF-1 $\alpha$ and its blockade under hypoxia enhanced MDSC-mediated T cell activation. J Exp Med 211: 781-790, 2014.

25. Clambey ET, McNamee EN, Westrich JA, Glover LE, Campbell EL, Jedlicka P, de Zoeten EF, Cambier JC, Stenmark KR, Colgan SP and Eltzschig HK: Hypoxia-inducible factor-1 alpha-dependent induction of FoxP3 drives regulatory T-cell abundance and function during inflammatory hypoxia of the mucosa. Proc Natl Acad Sci USA 109: E2784-2793, 2012 